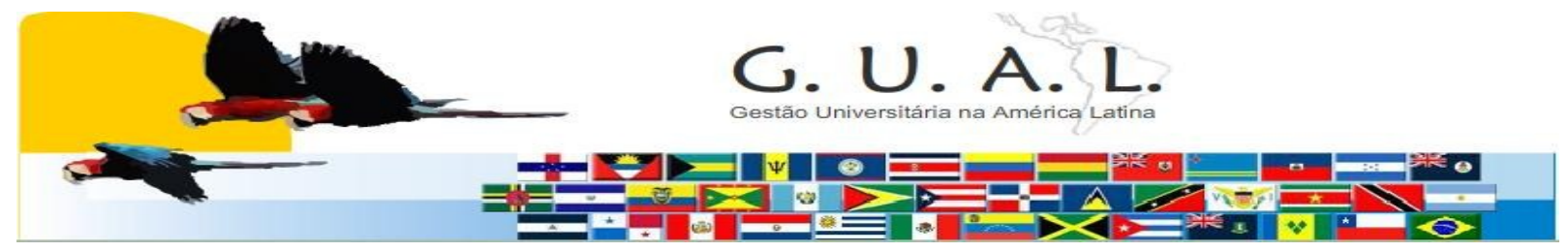

ISSN 1983-4535

\title{
O IMPACTO DA ESTRUTURA LEGAL DO PDI NO PROCESSO DE PLANEJAMENTO ESTRATÉGICO DE INSTITUIÇÕES DO SISTEMA AMPESC
}

\author{
Thiago Henrique Almino Francisco, Especialista \\ Universidade Federal de Santa Catarina - UFSC \\ thiagofrancisco@facierc.com.br \\ Alexandre Moraes Ramos, Doutor \\ Universidade Federal de Santa Catarina - UFSC \\ amrrms@gmail.com
}

\author{
Angela Regina Heinzen Amin Helou, Mestre \\ Universidade Federal de Santa Catarina - UFSC \\ aamim@uol.com.br
}

\author{
Expedito Michels, Especialista \\ Faculdade Capivari - FUCAP \\ expedito@fucap.edu.br
}

Nilo Otani, Doutor

Escola Superior de Criciúma - ESUCRI

ni_otani@yahoo.com.br

\section{RESUMO}

O artigo versa sobre o impacto dos instrumentos legais, relacionados à construção do Plano de Desenvolvimento Institucional (PDI), no processo de planejamento estratégico de instituições do sistema AMPESC que se localizam no sul do estado de Santa Catarina. A contribuição teórico-empirica elenca aspectos relacionados ao processo de avaliação da educação superior no Brasil, com ênfase na relação entre a avaliação, a regulação e a supervisão e o foco em seus eixos de construção. Também discute sobre a importância do documento para o desenvolvimento da avaliação institucional, culminando em uma reflexão sobre o planejamento estratégico nas instituições de educação superior. Para tanto, desenvolveu-se uma pesquisa descritiva-explicativa, predominantemente qualitativa, a partir da entrevista não estruturada e não disfarçada em uma amostra probabilista intencional com duas instituições do sistema AMPESC localizadas no sul de Santa Catarina. Entre outros aspectos, os resultados permitiram identificar que os principais instrumentos legais relacionados à construção do PDI causam impacto no desenvolvimento de questões estratégicas relacionadas a estrutura física e ao processo de posicionamento e expansão institucional, consolidando a identidade institucional e os processos regulatórios nas instituições pesquisadas.

Palavras-chave: PDI. Planejamento estratégico. Educação superior. 


\section{O IMPACTO DA ESTRUTURA LEGAL DO PDI NO PROCESSO DE PLANEJAMENTO ESTRATÉGICO DE INSTITUIÇÕES DO SISTEMA AMPESC}

\section{INTRODUÇÃO}

O processo de desenvolvimento da educação superior no Brasil, sobretudo a partir da orientação da Lei de Diretrizes e Bases da Educação Nacional de 1996 -LDB (1996), parte de um pressuposto que envolve a contribuição dos órgãos reguladores no processo de consolidação das práticas institucionais. As bases destas construções estão fundamentadas na proposta constitucional, orientando as ações que convergem para o atendimento aos termos descritos no Art. 209 da Constituição Federal (1988), onde são descritas as orientações gerais à atuação da livre iniciativa na educação superior.

Por intermédio destes instrumentos é que se desencadeou o que Garcia (2006) chama de liberalismo da educação superior, consolidando a atuação da iniciativa privada e promovendo o posicionamento do segmento como agente proativo no processo de desenvolvimento do Plano Nacional da Educação - PNE. Promulgado pela Lei 10.172, de 09 de janeiro de 2001, o plano propôs uma série de metas para o desenvolvimento da educação superior, sempre com as bases nos aspectos de qualidade e com a intenção de democratizar o acesso dentro as perspectivas descritas pela OCDE (2010).

O desenvolvimento técnico da educação superior no Brasil, especialmente na orientação do processo de expansão, deve estar vinculado a ações que estimulem os processos de democratização do acesso e a permanência, considerados vetores construtivos de uma realidade factível para o segmento privado da educação superior. Neste sentido, Frauches e Fagundes (2007) discutem sobre a importância de um instrumento que se tornou referência no processo de expansão da educação superior no País, especialmente pela consolidação dos aspectos alinhados a avaliação, a regulação e a supervisão da educação superior, o qual foi denominado de Plano de Desenvolvimento Institucional.

O PDI, na estrutura apresentada pelo Decreto 5773, de 09 de maio de 2006, está consubstanciado em eixos, alinhando ações aderentes ao processo de avaliação institucional e direcionando à compreensão do escopo da educação superior. Por fundamento, o documento consolidou a estrutura operacional da educação superior, convergindo aos procedimentos de avaliação, regulação e supervisão do processo educacional, elencando ações para cada um dos seus 10 eixos.

A partir desta orientação, os direcionamentos para a construção do documento podem estar diretamente relacionados com o processo de planejamento estratégico das instituições 


\section{O IMPACTO DA ESTRUTURA LEGAL DO PDI NO PROCESSO DE PLANEJAMENTO ESTRATÉGICO DE INSTITUIÇÕES DO SISTEMA AMPESC}

que se utilizam de tal instrumento para estruturar seu processo de desenvolvimento e expansão. Desse modo, o artigo se apresenta de maneira a buscar uma compreensão do impacto causado pelos instrumentos legais que compõem a construção do PDI no processo de Planejamento Estratégico de instituições do sul catarinense, vinculadas ao sistema AMPESC.

Para tanto, o artigo se divide em cinco capítulos, sendo que o primeiro busca uma abordagem introdutória. O segundo traz uma contribuição teórico-empirica sobre a avaliação, a regulação e a supervisão na educação superior, apresentando os aspectos relacionados ao Decreto 5773/06, à construção do Plano de Desenvolvimento Institucional e as bases do Planejamento Estratégico na educação superior. O terceiro apresenta a metodologia utilizada para a consolidação da pesquisa, enquanto o quarto capítulo sistematiza os resultados da investigação, culminando no quinto, e último, que traz as conclusões e sugestões para trabalhos futuros.

\section{A AVALIAÇÃO, A SUPERVISÃO E A REGULAÇÃO NA EDUCAÇÃO SUPERIOR}

As perspectivas apresentadas pelo Censo da Educação Superior, com dados do INEP (2011), descrevem um posicionamento da educação superior que determina a necessidade de constituir instrumentos que norteiem o desenvolvimento de um segmento que se expandiu em números exponenciais, praticamente triplicando o quantitativo de instituições em um período que compreendeu cinco anos. Ao considerar as discussões sobre o processo de avaliação no âmbito da qualidade, deve-se então analisar o Decreto 3860, de 09 de julho de 2001, o qual promoveu a estruturação da oferta do segmento privado, contribuindo para a construção de um contexto de desenvolvimento pautado nos aspectos de regulação, avaliação e supervisão da educação superior.

As instituições passaram a obedecer a aspectos instituídos por um instrumento legal que determinava direcionamentos vinculados à avaliação, à regulação e a supervisão da educação superior. Ao processo de avaliação, instituem-se variáveis que determinam a efetividade das ações institucionais no processo avaliativo, interagindo com o processo de regulação para orientar os processos de autorização de cursos e credenciamento institucional, além de proporcionar direcionamentos ao contexto da supervisão das instituições por meio de ações integradas entre as diversas autarquias e secretarias dos órgãos reguladores vinculadas à educação superior. 


\section{O IMPACTO DA ESTRUTURA LEGAL DO PDI NO PROCESSO DE PLANEJAMENTO ESTRATÉGICO DE INSTITUIÇÕES DO SISTEMA AMPESC}

No sentido da regulação, a proposta institui procedimentos operacionais para o credenciamento institucional e a autorização de cursos, exigindo uma interação relevante entre mantenedora e mantida para a consolidação da proposta institucional. Entre outros aspectos, os documentos institucionais ganham representatividade no processo de gestão, com destaque para os direcionamentos que convergiriam para a construção do Plano de Desenvolvimento Institucional.

Já ao processo de supervisão, tal como destaca Schwartzman (2004), é onde são estabelecidas as orientações normativas para o desenvolvimento das ações institucionais, as quais devem estar alinhadas às orientações das políticas públicas e determinar uma contribuição da instituição na oferta da educação superior de qualidade. Estes aspectos se delimitaram com o advento da proposta do SINAES, instituída pela Lei 10.861, de 14 de abril de 2004, constituindo uma concepção norteadora dos processos de interação entre a instituição e a sociedade por meio da consolidação da identidade institucional, justificando as contribuições sociais de uma instituição, tal como indica Dias Sobrinho (1995).

Apesar destes aspectos, o desenvolvimento da educação superior ainda necessitava de um instrumento normativo que alinhasse a atividade das instituições aos desígnios dos órgãos reguladores da educação superior no Brasil, o que ocorreu com a promulgação do Decreto $5773 / 06$.

\subsection{Decreto 5773/06: Norteador do Escopo da Educação Superior no Brasil}

Tal como destaca Frauches (2006), os objetivos do decreto se direcionavam para normatizar o exercício das funções institucionais, além de integrar ações que permitissem atender aos ensejos do Sistema de Avaliação vigente, o SINAES. Isso permitiu o alinhamento entre os cursos de graduação e a atuação das instituições no sistema federal, além de designar as competências dos diversos envolvidos nos processos relacionados entre a instituição e o Ministério da Educação - MEC.

Além de orientar estes aspectos, o documento promulgado em 2006 instituiu ações específicas que orientam a participação dos órgãos reguladores da educação superior, consolidando as atividades das secretarias do MEC, do Conselho Nacional da Educação CNE, do Instituto de Pesquisas e Estudos Educacionais Anísio Teixeira - INEP, da Comissão 


\section{O IMPACTO DA ESTRUTURA LEGAL DO PDI NO PROCESSO DE PLANEJAMENTO ESTRATÉGICO DE INSTITUIÇÕES DO SISTEMA AMPESC}

Nacional de Avaliação da Educação Superior - CONAES e, consequentemente, dos instrumentos de avaliação propostos pela Portaria $\mathrm{N}^{0} 300$, de 30 de janeiro de 2006.

Em conjunto com a Lei 10.861/2004, também conhecida como Lei do SINAES e que foi promulgada em 2004, o Decreto 5773/06 consolida o conceito de qualidade na educação superior, amplamente discutido por Frauches e Fagundes (2007) e que se posiciona de modo alinhado com a identidade de cada instituição. Assim como descrito nas evidências de Hékis (2004), a avaliação institucional em consonância com a proposta do Decreto determina a proposta pedagógica e administrativa da instituição, definindo seu papel social, sua estrutura e seu posicionamento na observância dos ensejos da sociedade.

Neste sentido, além de constituir o papel de cada modelo institucional no processo de expansão, o decreto passa a instituir as expectativas elencadas por Souza (2001), as quais passam a constituir procedimentos que devem ser atendidos por cada segmento dos órgãos da educação superior no Brasil. Tal como indica Frauches (2007), o Decreto 5773/03 promoveu a regulamentação do Art. $1^{\circ}$ da $\mathrm{LDB}$, orientando as atividades dos órgãos reguladores da educação superior no País, integrando os movimentos operacionais das instituições de modo a atender aos pressupostos designados à atividade funcional das instituições.

Às Secretarias vinculadas ao Ministério da Educação, instituem-se as funções de regulação e supervisão do sistema federal de educação superior, as quais passam a ser responsáveis por orientar as funções da educação presencial, educação profissional e tecnológica, e a educação a distancia. Já o Conselho Nacional da Educação, tal como destaca o Decreto 5773/06 e Frauches (2007), caberia a função de decidir sobre a sistematização das atividades das secretarias, atuando especificamente nos processos relacionados à regulação e a supervisão dos processos de credenciamento e recredenciamento institucional.

Já ao Instituto Nacional de Estudos e Pesquisas Educacionais Anísio Teixeira (INEP), autarquia responsável pelas operações vinculadas aos processos de avaliação institucional, caberia as funções de avaliação, operacionalizando o sistema constituído pela Lei $\mathrm{N}^{0}$ 10.861/04 e realizando os procedimentos operacionais para a consolidação da estrutura educacional do segmento da educação superior. Entre os diversos aspectos vinculados à sua estrutura, o Decreto 5773/06 alinhou os direcionamentos para os processos de autorização, reconhecimento e renovação de reconhecimento dos cursos de graduação, elaborando os 


\section{O IMPACTO DA ESTRUTURA LEGAL DO PDI NO PROCESSO DE PLANEJAMENTO ESTRATÉGICO DE INSTITUIÇÕES DO SISTEMA AMPESC}

instrumentos para os processos regulatórios e aplicando procedimentos sistemáticos para a verificação da qualidade de instituições e de cursos.

O decreto também se estendeu para o direcionamento das atividades da Comissão Nacional de Avaliação da Educação Superior (CONAES), responsável pela coordenação e supervisão do sistema de avaliação e pelo estabelecimento das diretrizes para a atividade das comissões de avaliação. As relações propostas pelo Decreto 5773/06 entre a avaliação, a regulação e a supervisão promoveram orientações à CONAES para desenvolver os instrumentos discutidos por Santos (2008), os quais se permeara um sistema de avaliação que valorizasse o posicionamento das instituições em um contexto de interação, intervenção e construção social.

Para tanto, o Decreto 5773/06 ainda traz uma inovação à atividade institucional ao estabelecer a estrutura do Plano de Desenvolvimento Institucional - PDI, o qual estaria diretamente relacionado ao desenvolvimento e a expansão da educação superior no Brasil. O arcabouço estrutural deste documento deveria contemplar as diversidades de cada modelo institucional, constituindo-se em um documento que compõe o processo de gestão institucional, tal como identifica Sousa (2007), servindo como subsidio estratégico no posicionamento da instituição.

\subsection{O Papel do PDI no processo de gestão institucional}

Em linhas gerais, o Plano de Desenvolvimento Institucional (PDI) tem a função de nortear as ações acadêmicas e administrativas que posicionam a instituição de educação superior em um contexto altamente complexo e competitivo. Nesta perspectiva, Collaço e Neiva (2006) referenciam o PDI alinhado a consolidação da autonomia às instituições, incorrendo êxito na proposição de valor apregoada por cada um dos modelos institucionais.

Apesar das discussões sobre a colaboração estratégica do PDI e suas relações com o planejamento estratégico, Santos (2008) destaca que o Plano de Desenvolvimento Institucional norteia a proposta pedagógica da instituição em uma perspectiva plurianual, desenvolvendo o projeto institucional de acordo com uma proposta objetiva, funcional e determinante aos intentos estratégicos da instituição. Em sua estrutura, tal como discutido por Sousa (2007), os direcionamentos acadêmicos e administrativos devem estar orientados para o desenvolvimento de políticas institucionais. 


\section{O IMPACTO DA ESTRUTURA LEGAL DO PDI NO PROCESSO DE PLANEJAMENTO ESTRATÉGICO DE INSTITUIÇÕES DO SISTEMA AMPESC}

Mormente no vértice desta orientação estrutural, o documento constitui-se em um instrumento fundamental ao processo de avaliação, já que é o mecanismo que retrata o escopo institucional, além de situar a instituição em um contexto, estabelecendo objetivos e políticas que permeiam o desenvolvimento da instituição. Por esta característica o PDI se posicionou como um instrumento de gestão que pode se tornar flexível na medida em que a instituição descobre as características de sua estrutura e de seu posicionamento, resultando na constituição de indicadores inerentes a atividade da instituição.

Em uma perspectiva funcionalista, a participação do PDI no processo gerencial está na ordenação e na organização dos objetivos institucionais, além de definir a área de atuação acadêmica da instituição. Esta construção permite o direcionamento de ações que visam posicionar a instituição em uma conjuntura competitiva, tal como destacada por Marquesi (2008), onde cabe aos diversos modelos institucionais perpassar os desafios apresentados pela ordem contemporânea.

Além destes aspectos, o PDI ainda permite que a instituição assuma sua responsabilidade no processo de construção e transferência de conhecimento, posicionando suas ações na perspectiva da indissociabilidade entre ensino, pesquisa, extensão e gestão. Independente de sua categoria administrativa, as quais foram discutidas por Souza (2001), o documento também posiciona os métodos de seleção de conteúdos e de direcionamento estrutural da instituição, os quais constituem nos pilares da identidade institucional, por meio de políticas alinhadas a dimensão.

Em uma conjectura estratégica, o PDI permite que a instituição constitua práticas gerenciais que convergem para o atendimento dos objetivos propostos em seus eixos, consolidando a eficácia da instituição no atendimento das políticas públicas e dos objetivos institucionais. Neste direcionamento, o documento permite que a instituição conheça suas potencialidades e constitua indicadores que permitam maximizar a eficácia de suas atividades, tal como destacado por Silva (2008), elencando e compartilhando a responsabilidade do cumprimento de sua missão.

Em epítome, o documento tem a função de constituir o pensamento gerencial da instituição, estabelecendo ações operacionais que determinem a identidade da instituição, orientando a qualidade das ações acadêmicas e administrativas da instituição, estabelecendo políticas institucionais validadas no processo de avaliação norteado pelos direcionamentos de 


\section{O IMPACTO DA ESTRUTURA LEGAL DO PDI NO PROCESSO DE PLANEJAMENTO ESTRATÉGICO DE INSTITUIÇÕES DO SISTEMA AMPESC}

SINAES (2009). Além destas características, o documento ainda tem suas funções e relações com os diversos instrumentos legais da educação superior, posicionando as atividades técnico-gerenciais nas bases das orientações legislativas aplicadas ao segmento da educação superior.

\subsection{Os eixos do Plano de Desenvolvimento Institucional}

A complexidade do ambiente da educação superior destacada por Rizzatti e Dobes (2004) determinou a estruturação de procedimentos gerenciais necessários ao desenvolvimento dos modelos institucionais brasileiros. Em linhas gerais, a evolução do segmento passou a requerer procedimentos sistematizados de gestão, aplicados a uma estrutura flexível e que se posiciona em um mercado altamente complexo e competitivo, sobretudo no segmento privado.

Por este aspecto, a atenção aos requisitos determinados pelo Decreto 5773/06 torna-se profícua, já que permitiu sistematizar a gestão nas instituições, colaborando com uma estruturação estratégica e para o que Tachizawa e Andrade (2006), Braga (2005) e Machado (2008) chamam de gestão profissional. Esta contribuição, sobretudo para o segmento privado, foi fundamental para constituir um cenário propicio ao desenvolvimento, alinhando as ações estratégicas, táticas e operacionais em um documento centrado em uma perspectiva quinquenal.

Diretamente relacionados com as dimensões propostas pela Lei do SINAES, o PDI se estruturou de modo a ponderar com as ações estratégicas, de tal modo que SINAES (2003) considera o Plano como sendo um referencial para a inserção da instituição em um contexto estratégico. Isso permite orientar e posicionar os gestores institucionais no contexto proposto ao desenvolvimento educacional no Brasil.

As orientações promovidas pelo Projeto Fortalece, uma iniciativa do Ministério da Educação (MEC) e do Instituto Nacional de Estudos e Pesquisas Educacionais Anísio Teixeira (INEP), que ocorreu em 2009 indicam que o primeiro eixo do documento destaca a construção do perfil institucional construindo, tal como elenca Collaço e Neiva (2006), os traços da identidade institucional proposta pela lei do SINAES. Em geral, o PDI busca descrever a missão da instituição e os objetivos descritos ao desenvolvimento de suas ações

Rev. GUAL., Florianópolis, Edição especial 2011, p.133-162. 


\section{O IMPACTO DA ESTRUTURA LEGAL DO PDI NO PROCESSO DE PLANEJAMENTO ESTRATÉGICO DE INSTITUIÇÕES DO SISTEMA AMPESC}

direcionadas a sua atividade acadêmica, em consonância aos intentos do Art. $16^{\circ}$ do Decreto 5773/06, evidenciando uma orientação estratégica arrolada a estrutura do documento.

A estrutura do segundo eixo busca delinear as políticas institucionais, alinhando as ações de modo a construir o projeto pedagógico institucional e direcionar as ações no âmbito acadêmico, ensejando a indissociabilidade entre ensino, pesquisa, extensão e gestão. As considerações do Projeto Fortalece (2009) destacam que neste eixo deve existir a menção sobre a responsabilidade social da instituição, especialmente no âmbito de sua proposta ao desenvolvimento social e econômico. Neste momento, são descritas as formas de promover um processo de construção científica, produção artística e cultural, além de alinhar as políticas de ensino, pesquisa, extensão e gestão no âmbito institucional, da graduação e da pósgraduação.

O terceiro e o quarto eixo se relacionam com a construção institucional no âmbito de seus cursos de graduação e pós-graduação, determinando o turno de funcionamento, o número de vagas e as considerações acerca da implantação e do desenvolvimento dos cursos no decurso da vigência do PDI. Destaca-se, em observância aos incisos III e IV do Art. $16^{\circ}$ do decreto 5773/06, que estes eixos devem determinar as informações sobre a expansão dos programas de graduação e especialização, em uma instituição não universitária, e de pósgraduação em nível de mestrado e doutorado para as instituições universitárias, o que é consolidado pela Resolução CES/CNE 1, de 2010 e pela Resolução CES/CNE 3 de 2010.

O eixo número cinco, tal como descrito pelas colocações discutidas no Projeto Fortalece (2009), destaca a organização didático pedagógica da instituição, descrevendo os parâmetros para a seleção de conteúdos e a elaboração dos currículos, considerando as inovações significativas propostas ao ensino e a metodologia utilizada no decurso dos projetos curriculares. Elenca também, aspectos vinculados aos recursos tecnológicos e aos procedimentos de interdisciplinaridade propostos pela instituição, consolidando as práticas pedagógicas inovadoras, as considerações sobre o estagio no contexto da Lei 11.788/2008 e as atividades complementares proposta pelas diretrizes curriculares nacionais para os cursos de graduação discutida por Frauches (2008).

Já o eixo número seis trata do perfil do corpo docente e técnico-administrativo da instituição, respeitando a identidade institucional e consolidando os critérios para a seleção e contratação de pessoal em atendimento aos desígnios do inciso V do Art.16 ${ }^{\circ}$ do Decreto 
5773/06. Fundamentado nas orientações do Projeto Fortalece (2009), deve-se destacar os requisitos de titulação e experiência na docência, além dos aspectos relacionados à experiência profissional, culminando na apresentação de um cronograma que determina a expansão do corpo docente no decurso do PDI.

Em consonância com este processo, o eixo ainda trata das políticas de qualificação, do plano de carreira, das considerações alinhadas ao regime de trabalho para instituições universitárias dentro dos parâmetros propostos pelo Decreto 5786/06, o qual foi sistematizado pela Resolução CES/CNE 1 de 2010 e pela Resolução CES/CNE 3 de 2010. De igual modo, o eixo trata das questões de qualificação, contratação e expansão do quadro de técnicosadministrativos, descrevendo os pontos específicos que se alinham à construção de um plano de carreira direcionado a expansão do corpo de colaboradores da instituição.

O sétimo eixo, tratado com atenção pelo Projeto Fortalece (2009), ampara a identidade institucional perante a comunidade acadêmica, já que trata da estrutura organizacional e administrativa da instituição. Desse modo, deve apresentar as principais características da estrutura organizacional, além de explicitar as formas de participação da comunidade acadêmica nos processos de tomada de decisão, culminando na estruturação do processo de avaliação institucional. Neste contexto, o eixo também destaca a articulação da instituição na observância das atividades de avaliação interna, descritas pela lei do SINAES (2004) de modo a constituir uma identidade baseada em pressupostos qualitativos e quantitativos, regulamentando as atividades consultivas da comissão própria de avaliação. Entre outros aspectos, o eixo também descreve os aspectos vinculados ao apoio pedagógico, aos programas de nivelamento e aos demais termos alinhados com a construção dos conceitos institucionais determinados pela Portaria Normativa 4, de 5 de agosto de 2008 e pela Portaria Normativa 12, de 5 de setembro de 2008 .

O eixo oito tem relação com o desenvolvimento dos procedimentos de avaliação em todos os seus momentos já que vai tratar da estrutura física da instituição que em todos instrumentos de avaliação é tratada como indicador substantivo para todos os atos regulatórios da instituição e dos cursos. Em seus aspectos principais, as orientações do Projeto Fortalece (2009) destacam que o eixo deve descrever as informações estruturais das bibliotecas disponíveis na instituição, as características do acervo por área de conhecimento e as políticas de atualização, além de destacar os recursos tecnológicos disponibilizados pela instituição 


\section{O IMPACTO DA ESTRUTURA LEGAL DO PDI NO PROCESSO DE PLANEJAMENTO ESTRATÉGICO DE INSTITUIÇÕES DO SISTEMA AMPESC}

para atender as necessidades de ensino. Também deve trazer a descrição dos serviços prestados, além das considerações sobre o pessoal técnico-administrativo da biblioteca, o horário de atendimento e as menções sobre os laboratórios disponíveis e as respectivas instalações para os cursos e programas de instituição. Além disso, o eixo também deve tratar dos equipamentos existentes e que serão adquiridos para cada laboratório, informando a relação de equipamento por número de acadêmicos disponível na instituição.

O eixo de número nove elenca questões vinculadas a inclusão, tratadas pelo Decreto 5773/06. Em seu arcabouço estrutural, traz considerações sobre as políticas e adequações da estrutura física que promovam a acessibilidade e $\mathrm{o}$ atendimento prioritário, imediato $\mathrm{e}$ diferenciado para portadores de necessidades especiais e deficiência física. Além disso, é relevante tratar das questões alinhadas ao atendimento das necessidades relacionadas a Língua Brasileira de Sinais (LIBRAS) e do cronograma de inclusão deste aspecto nos projetos de curso conforme os padrões estabelecidos pelo Decreto 5626/2005.

Por fim, na construção estrutural do PDI, o décimo eixo discute os aspectos vinculados a sustentabilidade econômico-financeira da instituição, apresentando os demonstrativos de capacidade e contemplando o decurso do plano e as ações para a promoção do ensino, da pesquisa, da extensão e da gestão, considerando a identidade institucional e orientando o orçamento relacionado também com o processo de planejamento no contexto institucional.

\subsection{Contribuições do planejamento estratégico na educação superior}

O planejamento estratégico na educação superior, assim como definido por diversos autores com destaque para Marcelino (2004), apresenta formas e métodos de utilização consolidados e aplicados à definição dos rumos institucionais e dos aspectos fundamentais do processo gerencial da instituição como organização. Sob a orientação deste pensamento, compreendendo a instituição de educação superior como organização, Mintzberg (1994) e Rigby (2001) se amparam em pressupostos qualitativos e destacam o planejamento estratégico como sendo um mecanismo de construção organizacional, consolidando técnicas de estruturação de informações necessárias a construção da estratégia.

No bojo de suas características, o planejamento estratégico é considerando uma ferramenta gerencial alinhada ao processo de tomada de decisão, o qual os executivos utilizam para compreender e posicionar a estratégia organizacional. Entre outros aspectos, 


\section{O IMPACTO DA ESTRUTURA LEGAL DO PDI NO PROCESSO DE PLANEJAMENTO ESTRATÉGICO DE INSTITUIÇÕES DO SISTEMA AMPESC}

pela relação do instrumento é possível compreender os ensejos do mercado e tornar a organização competitiva ao ponto de atender às solicitações de seus stakeholders.

No contexto organizacional, as definições de Ansoff (1991) trazem o planejamento estratégico como um método sistemático de controle de atividades estruturado com o objetivo de pontuar a estratégia organizacional em um determinado interregno de tempo. Com a utilização deste instrumento, torna-se possível conhecer perspectivas, prospectar cenários, construir alternativas e elencar meios, métodos e caminhos para compreender as necessidades organizacionais, auxiliando o processo de tomada de decisão.

Dentre as diversas definições, Mosimann e Fisch (1999) destacam que este processo sistemático tem relação com os objetivos e os meios organizacionais para a consolidação da proposta estratégica, definindo sentidos, significados e utilizando as diversas variáveis ambientais para a consolidação da proposta desejada. Entre outros aspectos, isso torna a organização dinâmica, permitindo que seus processos estejam alinhados às necessidades e a competitividade, impostas pelo mercado.

No contexto da educação superior Meyer Junior (2000) destaca que o planejamento estratégico é mecanismo que embasa as atividades institucionais em um contexto globalizado, complexo e competitivo, permitindo que as instituições estejam alinhadas às demandas ensejadas pelo seu ambiente. Isso confirma os direcionamentos de Whittington (2002), já que o planejamento estratégico na educação superior agrupa atividades específicas e vinculadas aos objetivos da instituição enquanto organização, posicionando-a frente as perspectivas de seu mercado.

À exemplo das demais organizações, Meyer Junior (2004) também afirma que as instituições de educação superior no contexto brasileiro estão a mercê do processo de evolução social, ensejando ações que delimitem o processo de construção do conhecimento por intermédio de inovações tecnológicas, da qualidade referendada no processo avaliativo e das mudanças constantes nas políticas educacionais. O planejamento estratégico, neste sentido, permite que a instituição construa formas eficazes de gerenciar seus objetivos, incorporando em sua estrutura as ações requeridas pelo ambiente, considerando seu desenvolvimento e o posicionamento em um âmbito de transformação.

Nesta conjectura, Baldridge (1983) destaca que o processo de planejamento estratégico na educação superior procura delimitar competitividade para promover efetividade 
e articulação em suas ações competitivas. Entre outros aspectos, isso deu origem a um processo de evolução do pensamento gerencial na estrutura das instituições, oferecendo instrumentos que permitiram a construção de métodos e técnicas de avaliação e controle da estratégia nas instituições de educação superior.

Isso se confirma no posicionamento de Salles (2007), já que o planejamento estratégico nas instituições de educação superior orienta as atividades vinculadas a ampliar a participação institucional no setor educacional, interpretando os questionamentos sugeridos pelo mercado, além de posicionar a instituição perante as necessidades da nova economia. De igual modo, ainda permite:

\begin{abstract}
A determinação de ações estratégicas com o objetivo de salvaguardar nichos de mercado e ampliar sua participação no setor de atuação é imperativa, tendo em vista as recentes mudanças provocadas por: a) mundialização da economia; b) maior nível de necessidades dos profissionais e das pessoas de se profissionalizar para o enfrentamento de uma concorrência cada vez mais acirrada em um mercado cada vez mais exigente; c) aumento do número de egressos do ensino médio, dispostos a seguir seus estudos e cursar o ensino superior; d) ampliação da oferta de instituições de ensino superior, bem como de vagas em seus cursos de graduação e seqüenciais; e) aumento da competitividade das escolas particulares pela conquista de novos alunos; f) exploração de áreas do saber antes fora do objeto de suas atenções; g) cumprimento das exigências legislativas em constantes mudanças; h) elevação de custos em decorrência das exigências do mercado; i) necessidade de aprimoramento da avaliação institucional das IES. Esta realidade de profundas mudanças torna complexo o processo de planejamento, a tomada de decisões e a adoção de ações para o sucesso empresarial. Tem-se, nesta situação, um desafio para administrar a organização neste novo ambiente (SALLES 2007, p. 35).
\end{abstract}

Percebe-se que o planejamento estratégico nas instituições de educação superior, independente da categoria administrativa, permite determinar ações flexíveis e determinantes ao sucesso da estratégia organizacional, confirmando os expostos de Selznick (1957), criando valor a estratégia da instituição. Além disso, também permite que a instituição ofereça respostas rápidas a um contexto complexo e competitivo tal como o destacado por Baldridge (1981), orientando atividades sistemáticas calcadas em procedimentos de controle tal como os descritos por Silva (2008).

Em resumo, este processo também permite que a instituição se adapte as mudanças requeridas pelo mercado, pelo ambiente ou pelo cenário, determinando orientações para o processo de gerenciamento do escopo institucional. Também permite a adequação ao escopo 


\section{O IMPACTO DA ESTRUTURA LEGAL DO PDI NO PROCESSO DE PLANEJAMENTO ESTRATÉGICO DE INSTITUIÇÕES DO SISTEMA AMPESC}

legal proposto pelos instrumentos que convergem à construção do Plano de Desenvolvimento Institucional - PDI -, os quais causam um impacto substantivo na estrutura institucional, sobretudo no segmento privado.

\section{ABORDAGENS METODOLÓGICAS}

Em consonância com os objetivos, as abordagens metodológicas se estruturam sob o processo de investigação proposto. Sob o lume dos pressupostos que orientam a problemática elencada, estruturam-se aportes específicos para promover a instrumentação necessária para sustentar a proposta do artigo. Em linhas gerais, a pesquisa estrutura-se pelas classificações propostas por Souza, Fialho e Otani (2007), além de contar com os esclarecimentos de Yin (2001), se inserindo no contexto do estudo de caso, já que procurou investigar aspectos específicos de duas instituições de educação superior que atuam no âmbito da livre iniciativa.

Os parâmetros de classificação da pesquisa apontam para as taxonomias descritas por Souza, Fialho e Otani (2007), tendo as bases concentradas na pesquisa acadêmica, sendo desenvolvida no contexto da educação superior e contribuindo ao desenvolvimento do grau acadêmico do autor, além de ofertar conhecimentos a uma determinada área do conhecimento.

Quanto à técnica empregada, a pesquisa considera a documentação indireta, já que utiliza-se de dados coletados por fontes primárias a partir da entrevista com os gestores das instituições pesquisadas, e de fontes secundárias, por meio das analises documentais dos objetos de estudo, sobretudo do Plano de Desenvolvimento Institucional. A pesquisa ainda se utiliza das resultantes da documentação direta, já que as entrevistas realizadas corroboram os dados ensejados com as investigações.

Conforme as descrições de Silva e Menezes (2005) e Souza, Fialho e Otani (2007), quanto à natureza, a investigação configura-se como sendo uma pesquisa básica, pois parte do pressuposto onde a construção de novos conhecimentos que não resulta no pronto atendimento as necessidades sociais. Ela corrobora com a intenção de promover ciência relevante e útil para o avanço de uma determinada área, neste caso a gestão da educação superior.

Já no contexto dos objetivos, com as bases em Zapelini e Zapelini (2007), Santos (2000) e Gil (2008), a pesquisa configura-se como sendo descritiva e explicativa, pois trata da descrição e da explicação do impacto dos instrumentos legais adjacentes à construção do PDI 
no processo de planejamento estratégico das instituições vinculadas ao sistema AMPESC e localizadas no sul do estado de Santa Catarina. Quanto a abordagem do problema, tal como indicam Souza, Fialho e Otani (2007), a investigação estrutura-se sob a orientação da pesquisa qualitativa, com a intenção de compreender a dinâmica dos instrumentos legais e a relação com o planejamento estratégico das instituições objeto de estudo.

No âmbito das fontes de informação, conforme Souza, Fialho e Otani (2007) a pesquisa utilizou a bibliografia disponível relacionada à construção do PDI, além dos roteiros informativos que destacam a orientação legal à construção do documento. Quanto aos procedimentos técnicos, a pesquisa configura-se como sendo bibliográfica, já que confirme Souza, Fialho e Otani (2007) utiliza-se de fontes e bibliografias relacionadas ao objeto de estudo, sobretudo ao planejamento estratégico, a educação superior e a construção do PDI. Também se estrutura sob a orientação documental, já que faz uso de documentos relacionados às instituições estudadas, considerada também uma pesquisa de campo, pelo fato da relação direta com as instituições estudadas e também uma pesquisa participante, já que o pesquisador participa ativamente do contexto no qual as instituições se inserem.

Ainda quanto aos procedimentos técnicos, Yin (2001) oferece subsídios para classificar a pesquisa como sendo um estudo de caso, configurando-se em um estudo multicaso. Isso ocorre, pois a pesquisa trata do foco na compreensão qualitativa do impacto dos instrumentos legais relacionados à construção do PDI no planejamento estratégico de duas instituições vinculadas ao sistema AMPESC e que se localizam no sul do estado de Santa Catarina. Portanto, os resultados não se limitam apenas a uma organização e permitem uma maior abrangência dos resultados, promovendo a compreensão da realidade estudada.

Com relação à população e a amostra, utilizam-se as percepções descritas por Marconi e Lakatos (2004) para descrever a contribuição dos pesquisados. No contexto da pesquisa, a população é composta de quatro instituições, tomando por base a amostragem não probabilística, já que a pesquisa se desenvolveu por um caráter específico de seleção dos elementos pesquisados. Por fim, utilizando-se de um roteiro de entrevista e das considerações de Triviños (2006), a investigação utiliza-se de um método não estruturado e não disfarçado de entrevista, já que é fundamental para delinear os propósitos do estudo aos respondentes no bojo da flexibilidade do método para elucidar o questionamento proposto pela problemática.

Rev. GUAL., Florianópolis, Edição especial 2011, p.133-162. 


\section{O IMPACTO DA ESTRUTURA LEGAL DO PDI NO PROCESSO DE PLANEJAMENTO ESTRATÉGICO DE INSTITUIÇÕES DO SISTEMA AMPESC}

\section{A CONTRIBUIÇÃO DA AMPESC À EDUCAÇÃO SUPERIOR CATARINENSE}

O desenvolvimento da educação superior, sobretudo pela promulgação da LDB (1996) e do Plano Nacional da Educação, em 2001, trouxe benefícios para o posicionamento das instituições como mecanismos de construção social. Isso se consolidou nas evidências propostas pelas orientações legais, avalizando a atuação da iniciativa privada sob pressupostos elencados pelos órgãos reguladores da educação superior no Brasil.

No contexto da expansão, tendo como objetivo principal a inserção de $30 \%$ dos acadêmicos entre 18 e 24 anos na educação superior, os dados do INEP (2011) mostram que o estado de Santa Catarina foi o que mais se aproximou deste número, chegando a um percentual de escolarização liquida de quase 17\%, pela incidência ações relacionadas ao acesso, a democratização e, principalmente, à interiorização da educação superior. Especialmente no estado catarinense, estas ações foram desenvolvidas pela força da iniciativa privada que promoveu o desenvolvimento das instituições públicas, as instituições "fundacionais" e vinculadas ao sistema ACAFE e, sobretudo, com as instituições do segmento privado de sentido estrito, tal como destaca Dittadi (2008).

O endereço institucional da AMPESC (2011) apresenta a Associação de Mantenedoras Particulares de Educação Superior de Santa Catarina - AMPESC - como entidade de classe que representa quase $90 \%$ do sistema privado do estado. Em sua estrutura, a associação abarca um número de 56 instituições associadas, sendo uma delas credenciada como centro universitário, tendo em sua estrutura mais de 120.000 acadêmicos entre a graduação, a pósgraduação lato-sensu e a pós-graduação scrito-sensu.

A entidade, que atualmente conta com 42 das 51 mantenedores existentes no estado de Santa Catarina, busca validar os interesses do segmento, prestando serviços que envolvem o escopo da educação superior e a mediação com os órgãos reguladores e outras entidades de classe. Dentre suas finalidades, destacam-se a colaboração com os poderes público e privados, visando o aprimoramento da educação superior e a proposta de serviços de assessoria nas diversas áreas de competência de uma instituição de educação superior.

Em síntese, a Associação torna-se um referencial na proposta de desenvolvimento da educação superior no estado de Santa Catarina, alinhando a consolidação do posicionamento e da representatividade do segmento privado da educação superior, contando, inclusive, com a cooperação da Associação Brasileira de Mantenedoras do Ensino Superior-ABMES. 


\section{O IMPACTO DA ESTRUTURA LEGAL DO PDI NO PROCESSO DE PLANEJAMENTO ESTRATÉGICO DE INSTITUIÇÕES DO SISTEMA AMPESC}

\subsection{Referências sobre as IES objeto de estudo}

No cenário sul catarinense, são cinco as instituições afiliadas ao sistema, com destaque para três instituições localizadas no município de Criciúma, outra localizada no município de Tubarão e uma em Capivari de Baixo. Isso retrata a que o sistema foi importante na interiorização da educação superior, permitindo que estas instituições contribuam com a consolidação dos objetivos do plano nacional da educação, atendendo uma faixa de quase 15 mil estudantes no contexto da graduação e da especialização.

Os critérios de seleção da amostra estiveram relacionados aos resultados do Conceito Preliminar de Curso e do Índice Geral de Cursos do ano de 2009, divulgados pelo INEP (2011). Neste sentido, a Instituição A, localizada no município de Criciúma, possui aproximadamente 600 acadêmicos no contexto da graduação e especialização, tendo obtido o IGC 3, em uma faixa contínua de 279, o que caracterizou o maior índice entre as instituições do sul do estado.

Já a Instituição B, localizada no município de Capivari de Baixo, insere-se no contexto da pesquisa pelo fato de possuir cinco (5) no Indicador de Diferença de Desempenho - IDD do curso de Administração, configurando um resultado em nível estadual e nacional. Entre outros aspectos, isso direciona uma percepção relacionada à preocupação das instituições no alinhamento suas ações estratégicas, táticas e operacionais ao seu Plano de Desenvolvimento Institucional - PDI, atuando para de compreender as influências dos instrumentos legais relacionados a sua construção e os impactos em seus processos de planejamento estratégico.

\subsection{Os instrumentos legais relacionados com o PDI}

O Plano de Desenvolvimento Institucional - PDI - tornou-se um documento referencial na proposta de consolidação dos modelos institucionais no âmbito da educação superior brasileira. Entre suas principais características, destacam-se as correlações com o processo de avaliação institucional, já que este procedimento é desenvolvido com base no PDI, orientado os processos regulatórios no âmbito do sistema federal de educação superior. É interessante perceber que, tanto na instituição "A", quando na instituição "B”, os impactos dos instrumentos legais podem ser considerados equivalentes, não pelo fato de imposições, mas sim pela preocupação de ambas as instituições com o desenvolvimento do PDI. 


\section{O IMPACTO DA ESTRUTURA LEGAL DO PDI NO PROCESSO DE PLANEJAMENTO ESTRATÉGICO DE INSTITUIÇÕES DO SISTEMA AMPESC}

Em ambas as instituições a Portaria 300 de 30 de janeiro de 2006, discutida em seus aspectos estruturais por Souza (2007), colima o PDI a partir de características que determinam a estrutura da instituição, além de orientar ações estratégicas no âmbito do posicionamento e da expansão institucional. Seu aspecto temporal permite a flexibilidade no processo gerencial, tornando-se um referencial para a tomada de decisão na instituição, especialmente para viabilizar o processo de expansão e desenvolvimento institucional.

Em seus aspectos estruturais, o PDI de ambas as instituições está alinhado com o que é destacado pelo Projeto Fortalece (2009), como um documento inerente a identidade institucional, sobretudo no traçado da filosofia de trabalho, abarcando aspectos estratégicos alinhados a missão institucional e as diretrizes de ensino sustentadas pela instituição. À expansão das ações institucionais, segue-se as considerações de Souza (2007) que destaca o PDI é um indicativo do desenvolvimento institucional, elencando as políticas institucionais de expansão, especialmente por intermédio de ações técnicas e estruturais desenvolvidas no contexto da instituição "A" e da instituição "B".

No arcabouço estrutural, as instituições consideram as bases de Santos (2008) e as orientações do Projeto Fortalece (2009), as quais salientam o aspecto legal que envolve o Plano de Desenvolvimento Institucional e que é intrinsecamente relacionado com os aspectos regulatórios da educação superior, assim como é destacado pela Portaria Normativa 23, de 01 de dezembro de 2010. Neste contexto, apesar de se constituir de forma livre, a estruturação do PDI deve estar pautada em aspectos legais, orientando o processo avaliativo e a consecução dos objetivos institucionais vinculados a regulação. Neste sentido, considerando o aporte legal no, nas instituições o documento tem suas bases centradas em instrumentos legais que permeiam o processo administrativo no âmbito da educação superior, com destaque para os instrumentos legais que orientam o desenvolvimento da educação no Brasil, sobretudo no segmento superior.

Tanto na instituição "A”, quando na instituição "B”, a LDB é considerada pela necessidade dos processos regulatórios e da avaliação da educação superior, subsidiando a construção e as respectivas atualizações do PDI, por meio das orientações que vão desde o processo de credenciamento institucional até o recredenciamento passando pelas autorizações, reconhecimento e renovação de reconhecimento dos cursos da instituição. Já a Lei 9784/99, regula o processo administrativo no âmbito publico federal, tendo sua relação direta com o 


\section{O IMPACTO DA ESTRUTURA LEGAL DO PDI NO PROCESSO DE PLANEJAMENTO ESTRATÉGICO DE INSTITUIÇÕES DO SISTEMA AMPESC}

documento de modo a oferecer subsídios e as normas básicas para que o PDI esteja em conformidade com os intentos dos órgãos reguladores em termos de estrutura e conteúdo.

A Lei do SINAES consolida o PDI no âmbito das instituições como referencial para a avaliação, indicando as orientações para a construção dos objetivos e as finalidades da instituição no contexto do ensino, da pesquisa, da extensão e da gestão. Isso culmina na construção de um relatório que, de acordo com a Portaria Normativa 23, é imprescindível para a continuidade dos processos regulatórios da instituição e deve ser submetido aos órgãos reguladores durante cada ano letivo.

O Decreto 5773/06, neste sentido, é o principal do documento no processo de construção do Plano de Desenvolvimento Institucional no âmbito das instituições, já que sistematizou os pontos relevantes dos instrumentos legais que o antecederam e proporcionou uma espécie de "roteiro" para a construção do documento. Apesar das alterações efetuadas pelo Decreto 6303/2007, o decreto consolida a construção do PDI e a manutenção da relação com os processos de avaliação. Entre as principais propostas pelo Decreto 5773/06, destacamse as orientações que devem constar no documento para a consolidação dos processos regulatórios na instituição, além das políticas institucionais para o ensino da graduação, da pós-graduação, da extensão e do atendimento a comunidade, culminando no atendimento às 10 dimensões propostas pela lei do SINAES.

Além destes, as instituições também consideram as orientações do Projeto Fortalece (2009), as quais destacam os instrumentos adjacentes à construção do PDI e que devem ser considerados no processo de desenvolvimento e acompanhamento do documento. Por sinal, estes instrumentos se destacam como sendo impulsionadores do pensamento, das intenções e das ações estratégicas, tal como destacado por Souza (2007), no bojo de uma estrutura institucional que atenda aos ensejos sociais.

De igual modo, tanto a instituição "A" quanto a instituição " $B$ ", tem a Lei 10.098/2000, que estabelece os critérios para a inclusão de pessoas portadoras de necessidades especiais, como um instrumento que impacta de modo direto na estrutura física da instituição, além da Portaria 3.284/03 e do Decreto 5.296/04, que regulamentam a matéria no âmbito educacional. Já o Decreto 5.224/2004, presta orientações às instituições federais, credenciadas como Centros Federais de Educação Tecnológica, mas também trazem um 
impacto, já que diz respeito aos aspectos estruturais e que trazem algumas referências ao segmento privado.

Deve-se considerar ainda mais alguns instrumentos referenciados pelas instituições objeto de estudo. A Portaria 2.051/2004 determina os procedimentos vinculados ao processo avaliativo, é um referencial neste direcionamento, consolidando as competências da Diretoria de Avaliação da Educação Superior - DESUP - pelo detalhamento das atribuições, permitindo que a construção do documento atenda aos ensejos desta instancia regulatória. Já a Portaria Normativa 23 de 01 de dezembro de 2010, sistematiza a construção do PDI e consolida o seu caráter temporal, fornecendo informações sobre impacto do documento nos processos regulatórios, além dos indicativos imprescindíveis que devem compor a estrutura do plano. Apesar de questionada no segmento privado, a portaria promove um direcionamento no processo de compreensão do PDI e das relações regulatórias, o que é fundamental para o andamento dos procedimentos regulatórios.

Por fỉm, além das proposições das Diretrizes Curriculares Nacionais sistematizadas por Frauches (2007), a Resolução CES/CNE 2 de 1998, que estabelece indicadores para a produção intelectual, para fins de credenciamento, e se relaciona com a pós-graduação stricto sensu, e a resolução CES/CNE 1/2007, que estabelece as normas para o funcionamento dos cursos de especialização, também contribuem para a consolidação do Plano de Desenvolvimento Institucional, sobretudo nas instituições pesquisadas.

\subsection{Impactos no processo de planejamento estratégico}

Tal como destacado por Machado (2008), os processos de planejamento e gestão estratégica no contexto do segmento privado da educação superior ainda estão em uma esfera muito aquém das expectativas institucionais. Com base nas considerações do autor, isso se dá em virtude da falta de conhecimento dos gestores, já que estes, em sua grande maioria, são de outras áreas de formação, fora do contexto gerencial. Neste caso, os principais prejuízos estão relacionados com a falta de conhecimento do processo de posicionamento institucional, o que prejudica a consolidação da instituição em um ambiente altamente complexo e competitivo.

Para as instituições objeto da pesquisa, o planejamento estratégico configura-se dentro das orientações de Pereira (2002), Marcelino (2004) e Pereira (2010), partindo do pressuposto no qual o estudo sistematizado dos construtos organizacionais e de suas relações com o 


\section{O IMPACTO DA ESTRUTURA LEGAL DO PDI NO PROCESSO DE PLANEJAMENTO ESTRATÉGICO DE INSTITUIÇÕES DO SISTEMA AMPESC}

ambiente consolidam os objetivos da organização, alinhando suas estratégias e construindo um alicerce para o desenvolvimento dos processos organizacionais. Desse modo, o objetivo desta prática é construir, ou aumentar, a competitividade por meio de ações empresariais que permitem uma situação favorável a consolidação do negócio da organização.

Nessa perspectiva, no âmbito das instituições pesquisadas, o processo de planejamento estratégico vai tratar do estudo e análise das forças e fraquezas organizacionais, além de promover indicadores que permitam atacar o mercado, otimizando as ações organizacionais frente aos concorrentes. Entre outros aspectos, assim como destacado por Welch e Byrne (2001), torna-se possível posicionar a organização em um contexto, no qual ela consiga atender ao mercado e compreender as principais características de seus concorrentes, além de estruturar os direcionamentos vinculados aos seus produtos, consolidando cenários, manobras específicas para compreender o mercado e atuação dos concorrentes.

Em epítome, as instituições consideram a proposta de Pereira (2010), que traz conceitos norteadores às organizações e as instituições pesquisadas, permitindo a construção de um cenário e prospecção de ações relevantes aos seus produtos, direcionando ações para a construção de um ambiente favorável. De modo didático e pragmático, este processo permite o entendimento das condições exigidas pelo mercado, além de combater pontos inerentes ao processo organizacional, sugerindo ações para minimizar riscos e diminuir o impacto de pontos fracos e ameaças vinculadas a estrutura organizacional.

As duas instituições pesquisadas estão em um momento de revisão de seu documento de planejamento estratégico, gerando resultados que estão perceptíveis no âmbito do entorno institucional. Na instituição "A", o impacto dos instrumentos legais relacionados a construção do PDI se dão na estruturação da ações, norteando as questões estratégicas relacionadas, especialmente, à estrutura física e de ensino, às ações relacionadas ao processo regulatório e ao processo de avaliação interna.

$\mathrm{Na}$ instituição "A", o exemplo se reflete na questão estratégica "qualidade das ações acadêmicas, estruturais e administrativas", socializando métodos e procedimentos internos de avaliação, respeitando as diretrizes do SINAES e da Portaria Normativa 23 que requerem ações da regulação interna da Instituição. Desse modo, retratam-se os impactos diretos das bases legais estruturais do PDI no processo de desenvolvimento e expansão institucional, com destaque para ações vinculadas aos aspectos que direcionam os processos administrativos, 


\section{O IMPACTO DA ESTRUTURA LEGAL DO PDI NO PROCESSO DE PLANEJAMENTO ESTRATÉGICO DE INSTITUIÇÕES DO SISTEMA AMPESC}

discutido por Brasil (1999), além dos aspectos regulatórios descritos no PDI e ensejados pelo Decreto 5773/06.

Já a Instituição "B" sofre os impactos dos instrumentos legais arrolados à construção do PDI em diversos aspectos de sua estrutura, mas com profundidade no alinhamento de sua visão e de questões estratégicas relacionadas a "ser uma instituição de excelência em educação superior". Identifica-se, com base na coleta de dados, que todos os instrumentos legais que versão sobre as instruções regulatórias estão plenamente respeitados no PDI da Instituição e servem de orientação a todas as ações estratégicas desenvolvida.

É valido ressaltar que, além dos impactos dos instrumentos vinculados à regulação, a Instituição analisou com maior profundidade a Portaria Normativa 23, promulgada em dezembro de 2010, incluindo ações estratégicas que estão relacionadas com um processo de revisão do PDI e de seus procedimentos internos de avaliação. Destaca-se também que, no âmbito da instituição "B", a preocupação com a regulação da educação superior trouxe grandes benefícios, sobretudo no último ciclo avaliativo.

\section{CONSIDERAÇÕES FINAIS}

A evolução da educação superior, especialmente por intermédio das ações do segmento privado, trouxe uma série de questionamentos relacionados à consolidação do sistema educacional brasileiro. O processo de avaliação institucional em voga instituiu uma série de obrigações e propostas vinculadas ao desempenho institucional e, sobretudo, ao processo de expansão qualitativo, permitindo que as instituições tomassem decisões baseadas em perspectivas vindouras.

Em consonância a esta perspectiva, surgem instrumentos legais que tem o objetivo de enriquecer o desenvolvimento do contexto institucional, no âmbito da construção de orientações e determinações para a consolidação do sistema. Desde a base constitucional, passando pela LDB e pelos demais atos normativos da educação superior, a construção do Plano de Desenvolvimento Institucional torna-se um processo sistemático que visa o desenvolvimento da educação superior nas bases de uma estrutura estratégica, incentivando a construção de uma cultura institucional que valorize a complexidade de cada identidade institucional. 


\section{O IMPACTO DA ESTRUTURA LEGAL DO PDI NO PROCESSO DE PLANEJAMENTO ESTRATÉGICO DE INSTITUIÇÕES DO SISTEMA AMPESC}

Isso permite a consolidação da identidade institucional, respeitando a estrutura e a concepção de cada instituição nas ações específicas que o PDI promove, garantindo a alavancagem de novas competências e o desenvolvimento sustentável do segmento educacional. Por este aspecto, torna-se importante que os diversos modelos institucionais compreendam as relações e os impactos causados pelos instrumentos legais contidos no arcabouço do PDI em seus processos estratégicos.

E com base nos dados levantados por intermédio da pesquisa, percebe-se que as instituições pesquisadas possuem o entendimento de seus respectivos ambientes de atuação e dos impactos causados pelos instrumentos legais alinhados à construção do Plano de Desenvolvimento Institucional. Apesar da proximidade no âmbito regional, estas possuem identidades diferentes e objetivos que versam sobre processos de expansão com focos diferenciados, utilizando o PDI como mote para a constituição de ações aderentes aos respectivos planejamentos estratégicos.

A instituição "A" ainda busca se posicionar em seu âmbito de atuação, especialmente fato de se tornar uma instituição de nicho que atenda a mercados estritamente relacionados com a sua identidade, utilizando os instrumentos legais no decurso da estruturação de ações estratégicas. Já a instituição "B”, que possui um planejamento arrojado e objetivos que convergem para um posicionamento competitivo e estruturado, identifica os impactos dos instrumentos legais a partir da análise de sua identidade institucional destacada no PDI, determinando questões estratégicas que consolidem seus métodos de atuação e posicionamento. Destarte, apesar da diferença entre as identidades e as perspectivas de posicionamento, ambas as instituições sofrem impactos semelhantes em seus respectivos processos de planejamento estratégico dos instrumentos legais vinculados à construção do PDI.

Por meio dos dados pesquisados pode-se inferir que os instrumentos legais causam diversos impactos no processo de planejamento estratégico das instituições pesquisadas, sobretudo no direcionamento das questões estratégicas e no processo de controle do Plano de Desenvolvimento Institucional, mas com um foco nos procedimentos regulatórios. Isso decorre do fato do PDI de ambas as instituições estarem diretamente relacionado com este processo, considerando os subsídios e orientações para a construção da identidade institucional e da avaliação da instituição. Estes processos são descritos pelo sistema de 
avaliação em voga como sendo preponderantes para o desenvolvimento, para a expansão e, por conseqüência, para o posicionamento em um segmento altamente competitivo e complexo.

A pesquisa também permitiu identificar que existem, pelo menos, 19 instrumentos legais que orientam a construção do PDI e que se classificam como leis, decretos, portarias, resoluções e pareceres, com destaque para o Decreto 5773/06 e que se ampara nos instrumentos maiores da educação superior no Brasil: a Constituição e a LDB. Com relação ao processo de planejamento estratégico das instituições pesquisadas, identifica-se que os impactos se dão especialmente no processo de levantamento das questões estratégia, as quais estão ligadas de modo direto ao processo de regulação e que é o principal à expansão. No âmbito destas instituições, por diversas orientações legais propostas a regulação, os instrumentos legais vinculados a construção do PDI trazem reflexões sobre as questões estratégicas, culminando em ações que respeitem o processo de regulação em sua totalidade.

As recomendações, para estudos futuros incluem ampliar o escopo de analise do questionamento apresentado, utilizando casos múltiplos e identificar os diferentes impactos dos instrumentos legais nos diversos modelos institucionais, englobando as diversas categorias administrativas e organizações acadêmicas que se encontram no segmento da educação superior no Brasil.

\section{REFERÊNCIAS}

AMPESC. Histórico da AMPESC. Disponível em:

$<$ http://www.ampesc.org.br/conteudo.php?codi=HIST>. Acesso em: 18/04/2011.

ANSOFF, H.I. A nova estratégia empresarial. São Paulo: Atlas, 1991.

BALDRIDGE, J.V. Strategic planning in higher education: does the emperor have any clothes? In: BALDRIDGE, J.V.; DEAL, T. The Dynamics of Organizational Change in Education, Berkeley: McCutchan, 1983.

BRAGA, Ryon. Análise setorial do ensino superior privado no Brasil: tendências e perspectivas 2006 - 2010. São Paulo: Hoper. 2005.

BRASIL. Constituição: República Federativa do Brasil, Brasília: Senado Federal, Centro Gráfico, 1988. 
BRASIL. Lei de diretrizes e Bases da Educação Nacional. Acesso em 10/04/2011. Disponível em: <http://www.planalto.gov.br/ccivil_03/Leis/L9394.htm>. 1996.

BRASIL. Resolução CES No 2 de 7 de abril de 1998. Acesso em: 18/04/2011. Disponível em: < http://www.proplan.ufam.edu.br/RESCES21998.pdf>. 1998.

BRASIL. Lei No 9.784, de 29 de janeiro de 1999. Acesso em: 1804/2011. Disponível em: $<$ http://www.planalto.gov.br/ccivil 03/Leis/L9784.htm>. 1999.

BRASIL. Lei $\mathbf{N}^{\mathbf{0}} \mathbf{1 0 . 0 9 8}$, de 19 de dezembro de 2000. Acesso em: 18/04/2011. Disponível em: $<$ http://www.planalto.gov.br/ccivil_03/Leis/L10098.htm>. 2000.

BRASIL. Lei $\mathbf{N}^{\mathbf{0}}$ 10.172, de 9 de janeiro de 2001. Acesso em 10/04/2011. Disponível em: $<$ http://www.planalto.gov.br/ccivil_03/leis/leis_2001/110172.htm>. 2001a.

BRASIL. Decreto 3.860 de 09 de julho de 2001. Acessado em: 10/04/2011. Disponível em: $<$ http://portal.mec.gov.br/sesu/arquivos/pdf/DecN3860.pdf $>$. 2001 b.

BRASIL. Portaria No 3.284, de 7 de novembro de 2003. Acesso em: 18/04/2011.

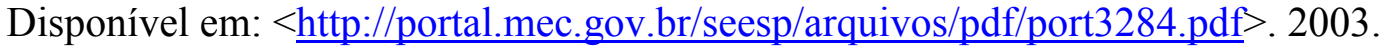

BRASIL. Lei 10.861, de 14 de Abril de 2004.. Acesso em: 10/04/2011. Disponível em: $<$ http://portal.mec.gov.br/arquivos/pdf/leisinaes.pdf $>$. 2004a.

BRASIL. Decreto No 5.296, de 2 de dezembro de 2004. Acesso em: 18/004/2011.

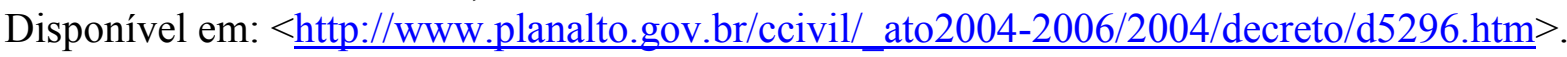
2004b.

BRASIL. Decreto No 5.224 de 1 de outubro de 2004. Acesso em: 18/04/2011. Disponível em: < http://www.planalto.gov.br/ccivil 03/ ato2004-2006/2004/decreto/d5224.htm>. 2004c.

BRASIL. Portaria No 2.051, de 9 de julho de 2004. Acesso em: 18/04/2011. Disponível em: $<$ http://www.faex.edu.br/v2009/cpa/Portaria.pdf $>$. 2004d.

BRASIL. Decreto $\mathbf{N}^{\mathbf{0}}$ 5.625, de 22 de dezembro de 2005. Acesso em: 11/04/2011.

Disponível em: $<$ http://www.planalto.gov.br/ccivil_03/_ato2004-

2006/2005/decreto/d5626.htm>. 2005.

BRASIL. Decreto 5773 de 9 de maio de 2006. Acesso em 10/04/2011. Disponível em: $<$ http://www.planalto.gov.br/ccivil 03/ ato2004-2006/2006/Decreto/D5773.htm>. 2006a.

BRASIL. Portaria $\mathbf{N}^{\mathbf{0}}$ 300, de 30 de janeiro de 2006. Acesso em: 11/04/2011. Disponível em:

$<$ http://www.einsteinlimeira.com.br/comissoes/cpa/arquivos/legislacao/Portaria\%20n.\%20300 $\% 20 \mathrm{de} \% 2030 \% 20 \mathrm{de} \% 20$ janeiro $\% 202006 . \mathrm{pdf}>$. $2006 \mathrm{~b}$.

Rev. GUAL., Florianópolis, Edição especial 2011, p.133-162. 
BRASIL. Decreto 5786, de 24 de maio de 2006. Acesso em 11/04/2011. Disponível em: $<$ http://www.planalto.gov.br/ccivil 03/ Ato2004-2006/2006/Decreto/D5786.htm>. 2006c.

BRASIL. Decreto $\mathbf{N}^{\mathbf{0}}$ 6.303, de 12 de dezembro de 2007. Acesso em: 18/04/2011.

Disponível em: $<$ http://www.planalto.gov.br/ccivil_03/_Ato2007-

2010/2007/Decreto/D6303.htm>. 2007a.

BRASIL. Resolução No 1, de 8 de junho de 2007. Acesso em: 18/04/2011. Disponível em: $<$ http://portal.mec.gov.br/cne/arquivos/pdf/rces001 07.pdf $>$. $2007 \mathrm{~b}$.

BRASIL. Lei 11.788 de 25 de setembro de 2008. Acesso em 11/04/2011. Disponível em:

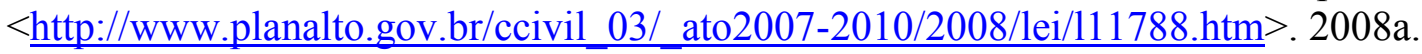

BRASIL. Portaria Normativa No 4, de 5 de agosto de 2008. Acesso em: 11/04/2011. Disponível em: $<$ http://www.anaceu.org.br/conteudo/legislacao/portarias/2008\%20\%20Portaria $\% 20$ Normativa $\% 204 \% 20-\% 205 \% 20$ agosto $\% 20-\% 20$ Republicada.pdf $>$. $2008 \mathrm{~b}$.

BRASIL. Portaria Normativa $\mathbf{N}^{\mathbf{0}}$ 12, de 5 de setembro de 2008. Acesso em 12/04/2011. Disponível em:

$<$ http://www.unicerp.edu.br/ensino/editais/cpa/PORTARIA NORMATIVA 12\%20\%20IGC \%2005_09_2008.pdf $>$. 2008c.

BRASIL. Instrumento de analise do PDI atualizado. In: Projeto Fortalece - Fortalecendo as competências dos profissionais da educação superior. Florianópolis. CDROM. 2009.

BRASIL. Resolução CES/CNE N 1, de 20 de janeiro de 2010. Acesso em: 11/04/2011. Disponível em:

$<$ http://portal.mec.gov.br/index.php?Itemid=866\&id=14917\&option=com content\&view=arti cle> $.2010 \mathrm{a}$.

BRASIL. Resolução CES/CNE Nº 3, de 14 de outubro de 2010. Acesso em: 11/04/2011. Disponível em:

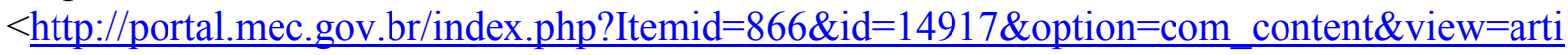
cle> $2010 \mathrm{~b}$.

BRASIL. Portaria normativa $\mathbf{N}^{0} 23$ de 01 de dezembro de 2010. Acesso em: 12/04/2011. Disponível em:

$<$ http://www.semesp.org.br/portal/pdfs/juridico2011/Portarias/Janeiro/PORTARIA\%20N\%20 23\%20-1-12-10.pdf>. 2010c.

COLLAÇO, Flávio Roberto. NEIVA, Claudio Cordeiro. Temas atuais de educação superior. ABMES Editora. Brasília: 2006.

DIAS SOBRINHO, J. Universidade: processos de socialização e processos pedagógicos. In: BALZAN, Newton César; DIAS SOBRINHO, José. Avaliação institucional: teoria e experiências. São Paulo: Cortez, 1995.

Rev. GUAL., Florianópolis, Edição especial 2011, p.133-162. 
DITTADI, Jair Roberto. Práticas de controladoria adotadas no processo de gestão de Instituições de Ensino Superior estabelecidas no Estado de Santa Catarina. Dissertação. (Mestrado). 210 fls. Programa de Pós-Graduação em Ciências Contábeis. Universidade do Vale do Rio dos Sinos. Porto Alegre, 2008.

FRAUCHES, C. (Org). Diretrizes curriculares nacionais para os cursos de graduação. Brasília. ABMES Editora. 2008.

FRAUCHES, Celso. Decreto ponte ou decretão: anotações preliminares. Brasília. ILAPE/ABMES. 2007.

FRAUCHES, Celso.C.; FAGUNDES, Gustavo. M, LDB Anotada e Comentada e Reflexões sobre a Educação Superior. 2 ed. Brasília: 2007.

GARCIA, Mauricio. Gestão Profissional em Instituições Privadas de Ensino Superior: um "guia de sobrevivência" para mantenedores, acionistas, reitores, pró-reitores, diretores, coordenadores, gerentes e outros gestores institucionais. Brasil: Hoper, 2006.

GIL, Antonio Carlos. Como elaborar projetos de pesquisa. 4. ed. São Paulo: Atlas, 2008.

HÉKIS. Hélio Roberto. Balanced scorecard: proposta de indicadores para monitorar e avaliar projetos pedagógicos dos cursos de graduação: o caso da faculdade Estácio de Sá de Santa Catarina. Tese (Doutorado). 221 fls. Programa de Pós-Graduação em Engenharia da Produção. Universidade Federal de Santa Catarina. Florianópolis. 2008.

INEP/MEC. Censo da Educação Superior 2009. Brasília: Ministério da Educação, 2011.

MACHADO, Luis. E. Gestão Estratégica para instituições de ensino superior privadas. 1 ed. - São Paul: FGV Editora 2008.

MARCELINO, Gileno F.(Org,); Gestão Estratégica de Universidade. 1 ed. Brasília: Editora UNB, 2004.

MARCONI, Marina de Andrade; LAKATOS, Eva Maria. Metodologia científica: ciência e conhecimento científico, métodos científicos, teoria, hipóteses e variáveis, metodologia jurídica. 4. ed. São Paulo: Atlas, 2004.

MARQUESI, Sonia.C. O papel do dirigente universitário no envolvimento da comunidade acadêmica para a construção do plano de desenvolvimento institucional. Monografia apresentada no IGLU, XIX Curso de Especialização em Administração Universitária, Porto Alegre, 2008.

MEYER JR, Vitor. Planejamento Universitário: Ato Racional, Político ou Simbólico - Um estudo de Universidades Brasileiras. In:28 Encontro Nacional da Associação Nacional de Pós 
-graduação em Administração - ENANPAD, 25 - 29 set. 2004. Curitiba. Anais. ANPAD, 2004.

MEYER JR., Victor. Novo contexto e as habilidades do administrador universitário. In:

MEYER JR., Victor; MURPHY, J. P. Dinossauros, gazelas e tigres. Florianópolis: Insular, 2000 .

MINTZBERG, Henry. The rise and fall of strategic planning. New York: Freeman, 1994.

MOSIMANN, C. P.; FISCH, S. Controladoria: seu papel na administração de empresas. 2. ed. São Paulo: Frase, 1999.

OCDE. Education at a glance: OCDE indicator. Organization for economic co-operation and development, 2010.

PEREIRA, Mauricio Fernandes Mudança estratégica em uma organização hospitalar: Um estudo de caso dos últimos 20 anos. Florianópolis, 1996. Dissertação (Mestrado em Engenharia da Produção) Programa de Pós-Graduação em Engenharia de Produção, UFSC,1996.

PEREIRA, Mauricio Fernandes. O Processo de Construção do Planejamento Estratégico através da Percepção da Coalizão Dominante. Florianópolis, 2002. 294 f. Tese (Doutorado em Engenharia de Produção) Programa de Pós-Graduação em Engenharia de Produção, UFSC, 2002.

PEREIRA, Mauricio Fernandes. Planejamento estratégico: teorias, modelos e processos. 1ed. São Paulo: Atlas, 2010.

RIGBY, Daniel. Management Tools and Techniques: a Survey. In. California Management Review, Vol. 43, no 2, winter 2001, pp. 139 - 160.2001.

RIZZATI, Gerson. DOBES, Cantalicia Elaine I. A complexidade do processo decisório em universidades, In: MELO, Pedro Antonio de. COLOSSI, Nelson. Cenários da Gestão Universitária na Contemporaneidade. Florianópolis, Editora Insular. 2004.

SALLES. Paulo Eduardo Marcondes de. Elaboração e Implantação de um novo Modelo de Gestão em Mantenedora de Instituição de Ensino Superior: o Caso da União Social Camiliana. Tese. 147. fls. (Doutorado em Engenharia de Produção) - Programa de Pós Graduação em Engenharia de Produção, Universidade Federal de Santa Catarina, Florianópolis, 2007.

SANTOS, Sérgio Ricardo Bezerra dos. O Balanced scorecard como instrumento de gestão à luz dos indicadores do Sistema Nacional de Avaliação da Educação Superior. Dissertação (Mestrado).182fls. Programa de Pós-Graduação Multiinstitucional e Interregional em Ciências Contábeis. Universidade de Brasília, Universidade Federal da Paraíba, Universidade Federal do Rio Grande do Norte. João Pessoa, 2008. 
SCHWARTZMAN, Simon. O enigma do ENADE. Disponível em: <www.schwartzman.org.br>.Acesso em: 12 dez. 2004.

SELZNICK, P. Leadership in Administration: a sociological interpretation. Evanston: Row, Peterson, 1957.

SILVA, G.J.C. O ensino superior privado: o confronto entre lucro, expansão e qualidade. 2008. 282f. Tese (Doutorado). Programa de Pós-Graduação em Ciências Sociais.

Universidade de Brasília. Brasília, 2008.

SILVA, Edna Lúcia de; MENEZES, Estera Muszkat Metodologia da pesquisa e elaboração de dissertação. UFSC, revista atualizada - 4ª ed. Florianópolis, Brasil. 2005

SINAES. Sistema nacional de avaliação da educação superior: da concepção à regulamentação. 5ed., revisada e ampliada - Brasília: INEP, 2009.

SOUZA, Paulo Nathanael Pereira de. LDB e educação superior: Estrutura e funcionamento. 2ed. Revista e ampliada. São Paulo. Pioneira Thomson Learning. 2001.

SOUZA, Antonio. C.; FIALHO, Francisco. A. P.; OTANI, Nilo. TCC Métodos e Ténicas. $1^{\text {a }}$ Ed. Florianópolis: Visualbooks, 2007.

SOUZA, José Carlos Victorino. Gestão universitária em instituições particulares: Os documentos institucionais como indicadores do modelo de gestão. Tese (Doutorado). 208 fl.Programa de Pós-Graduação em Educação e currículo. Pontifícia Universidade Católica de São Paulo, 2007.

TACHIZAWA, Takeshi; ANDRADE, Rui.Otávio.B. Gestão de instituições de ensino. 4ed. rev. e ampl. Editora FGV. Rio de Janeiro. 2006.

TRIVIÑOS, Augusto Nibaldo Silva. Introdução à pesquisa em ciências sociais: a pesquisa qualitativa em educação. São Paulo: Atlas, 2006.

YIN, Robert. Estudo de caso: planejamento e métodos. 4ed. Porto Alegre. Bookman. 2001.

WELCH, Jack. BYRNE, J.A. Jack definitivo: segredos do executivo do século. Rio de Janeiro: Campus, 2001.

WHItTINGTON, R. O que é estratégia. São Paulo: Pioneira Thomson Learning, 2002.

ZAPELINI, Marcelo.B; ZAPELINI, Silvia.M.K.C. Metodologia científica e da pesquisa para o curso de Administração. Apostila do curso de Administração. Faculdade Energia de Administração e Negócios, 2007. 


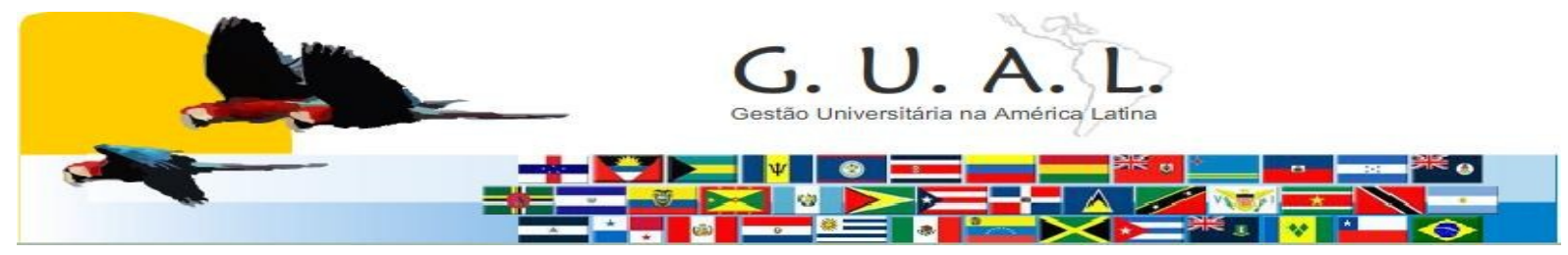

ISSN 1983-4535

\title{
THE IMPACT OF LEGAL STRUCTURE OF PDI IN STRATEGIC PLANNING PROCESS OF SYSTEM INSTITUTIONS AMPESC
}

\author{
Thiago Henrique Almino Francisco, Specialist \\ Universidade Federal de Santa Catarina - UFSC \\ thiagofrancisco@facierc.com.br \\ Alexandre Moraes Ramos, Doctor \\ Universidade Federal de Santa Catarina - UFSC \\ amrrms@gmail.com
}

\author{
Ângela Regina Heinzen Amin Helou, Master \\ Universidade Federal de Santa Catarina - UFSC \\ aamim@uol.com.br
}

\author{
Expedito Michels, Specialist \\ Faculdade Capivari - FUCAP \\ expedito@fucap.edu.br
}

Nilo Otani, Doctor

Escola Superior de Criciúma - ESUCRI

ni_otani@yahoo.com.br

\begin{abstract}
Article contextualizing lecture on the impact of legal instruments related to the construction of the Institutional Development Plan (IDP) in the process of strategic planning system AMPESC institutions that are located in the southern state of Santa Catarina. The contribution of theoretical and empirical lists aspects of the process of evaluation of higher education in Brazil, with emphasis on the relationship between evaluation, regulation and supervision of higher education in Brazil and terms related to PDI, with a focus on their axes and construction the importance of the document for planning, development and institutional assessment, culminating in a reflection on strategic planning in institutions of higher education. For this purpose, we developed a descriptive and explanatory, largely qualitative, from the unstructured interview and not disguised in a probabilistic sample with two intentional system institutions AMPESC located in southern Santa Catarina. Among other things, the results showed that the main legal instruments related to the construction of PDI impact the development of strategic issues related to physical structure and the process of institutional placement and expansion, consolidating the institutional identity and regulatory processes in the institutions surveyed.
\end{abstract}

Keywords: PDI. Strategic planning. Higher education. 